\title{
DIVULGAÇÃO ARTÍSTICO-CIENTÍFICA: A COMUNICAÇÃO DA PESQUISA EM ARTE COMO FERRAMENTA PARA A HISTÓRIA DA ARTE CONTEMPORÂNEA
}

Tânia Ribeiro Soares ${ }^{1}$

\section{Resumo}

A Artemídia, forma de expressão artística contemporânea em constante transformação graças a sua gênese nas novas tecnologias e na figura do artista-pesquisador, evidencia as relações entre Arte e Ciência, impondo um novo desafio no âmbito da divulgação científica: comunicar a pesquisa em Arte com o mesmo rigor acadêmico das pesquisas em diferentes áreas. Esse é o tema do projeto "Divulgação Artístico-Científica: Artemídia Veemente", desenvolvido no Instituto de Artes da Unesp. O presente trabalho coloca a participação da pesquisadora no II Encontro de História da Arte da Unicamp como um experimento prático do projeto. Relacionando História e Jornalismo, o presente trabalho aponta a importância da divulgação científica da Artemídia como fonte para comunicadores, divulgadores de ciência e historiadores da arte.

Palavras-chave: Divulgação Científica, História da Arte, Pesquisa em Arte.

\section{Tubo de ensaio: a participação no II EHA como experimento de pesquisa ${ }^{2}$}

A pesquisa "Divulgação Artístico-Científica: Artemídia Veemente", atualmente em desenvolvimento sob orientação do Prof. Dr. Pelópidas Cypriano PEL, livre docente do Instituto de Artes da Unesp, supervisão jornalística de Oscar D’Ambrosio e patrocínio do Programa Mídia Ciência da Fundação de Amparo à Pesquisa do Estado de São Paulo (FAPESP), parte dos pressupostos da divulgação científica para buscar formas e instrumentos de disseminação da pesquisa em arte. Sendo a comunicação da pesquisa entre pares, por meio da participação de encontros, seminários e congressos científicos, entre outros, um dos primeiros passos da divulgação científica, a presença da pesquisadora no II Encontro de História da Arte, realizado pelo Instituto de Filosofia e Ciências Humanas da Unicamp, é tomada como uma experiência de fundamental importância para o processo de pesquisa.

No II EHA encontrou-se a ressonância de que se precisa para realizar a divulgação dessa 'pesquisa sobre como divulgar pesquisas', sendo o evento ao mesmo tempo mídia e 'tubo de ensaio'. Durante a comunicação, a 'reação dos elementos' vai ajudar a descobrir o sucesso do experimento, mas diferentemente das experiências científicas tradicionais, nesse trabalho "ao vivo" com o objeto de pesquisa não se busca uma fórmula exata e, sim, uma reflexão acerca de todo o processo.

Nos últimos meses, o Instituto de Artes revelou uma grande necessidade de potencializar o acesso público às pesquisas realizadas em seus programas de pós-graduação em Artes. Mais do que um volume de dissertação para a biblioteca e um título de mestre ao autor, várias pesquisas resultam no Trabalho Equivalente - obras de arte, exposições ou protótipos de produtos artísticos, de design e/ou editoriais, que perderiam seu valor se

\footnotetext{
${ }^{1}$ Jornalista, bolsista do programa Mídia Ciência da Fundação de Amparo à Pesquisa do Estado de São Paulo, Instituto de Artes da Unesp - Lato sensu História da Arte e Cultura Contemporânea. Email: taribeiro@uol.com.br.

2 Embora obedeça às regras formais estabelecidas pelo EHA e pela ABNT, este trabalho utiliza recursos do estilo jornalístico tais como lead e registro da experiência de repórter, além de algumas metáforas poéticas dentro da relação Arte-Ciência.
} 
ficassem engavetados. Aliás, assim é a pesquisa em arte - procura que orienta o fazer artístico e resulta em obra, ou nas palavras de Silvio Zamboni: "a pesquisa realizada pelos artistas, ou seja, quando o artista também se assume como pesquisador e busca, com essa dupla face, obter trabalhos artísticos como resultado de suas pesquisas". (ZAMBONI, 2001, p. 6)

Acredita-se que comunicando e potencializando o acesso público a essas obras e suas respectivas pesquisas, o Instituto de Artes da Unesp estará contribuindo não só para a produção artística contemporânea como para o reconhecimento da Artemídia como meio de construção e transmissão de conhecimento.

\section{Para contar a Arte do nosso tempo}

História e Jornalismo têm em comum o trabalhar com tempo. Ao jornalista interessa o imediato, o tal "aqui-agora", o registro dos fatos do dia, da hora e, com o advento das novas tecnologias de comunicação, do "último segundo", para cumprir outro de seus papéis, informar, comunicar, divulgar, tornar "vulgar", ou seja, conhecido, acessível a todos. No momento seguinte, recomeçam as buscas por novas notícias, novas descobertas, reforçando uma frase muito conhecida entre os profissionais da área "Nada mais velho do que um jornal de ontem". Velho? Não para o historiador, que tem outra relação com o tempo e outra maneira de trabalhar com os periódicos que, em suas mãos, transformam-se em documento. De uma forma bem simples, já que essa relação em si já seria assunto para uma outra pesquisa, pode-se-ia dizer que jornalistas e historiadores têm uma relação de livre troca em suas ações com os fatos, um fornecendo ao outro subsídios e material de trabalho. O jornalista se vale do conhecimento histórico para compreender a importância e os possíveis desdobramentos de um acontecimento; e o historiador, como já exemplificado antes, apóia-se, entre outras fontes, na produção jornalística para registrar a História.

A Divulgação Artístico-Científica, tema desta pesquisa, consiste em encontrar meios de comunicar as pesquisas em arte nos mesmos moldes e com o mesmo rigor com que é divulgada a produção científica em outras áreas do conhecimento. É o jornalismo científico voltado para a produção artística, que poderá ter para o historiador da arte o mesmo valor que os periódicos em geral têm para o historiador que lida com política ou economia, por exemplo.

O tempo também é matéria do artista em qualquer época. Seja qual e como for, a produção artística de um determinado período estará intrinsecamente ligada a esse ser-estar no tempo do artista. Os Renascentistas e sua perspectiva linear representaram a visão de mundo centrada no homem, uma das mais marcantes características do período; séculos mais tarde, outros artistas procuraram outras soluções formais ou materiais para representar as transformações desse ser-estar no mundo, como Vincent Van Gogh e sua distorção da perspectiva; Jackson Pollock com sua nova técnica de pintura representando uma nova relação com o espaço, só para citar alguns exemplos dessa relação do artista e seu tempo.

Da mesma maneira, identificam-se nas obras de arte contemporâneas características marcantes do tempo presente nos temas, nas soluções formais e no uso da tecnologia. É nesse contexto em que se insere uma modalidade de criação que se transforma com e como o momento histórico em que vivemos, inclusive seu próprio nome, a Artemídia, também chamada Mídia-Arte ou Arte Tecnologia. 
Quando se fala de tecnologia não se trata apenas do "high-tech", das descobertas de ponta, mas sim de tecnologia como conhecimento materializado, reforçando que as tangências e intersecções entre Arte e Ciência sempre existiram. O que muda nessa dicotomia Arte-Ciência na contemporaneidade, tempo de buscas de conhecimento cada vez mais profundas, relações sociais mais complexas e aparatos tecnológicos mais avançados e como tudo isso afeta o homem é objeto e tema do artista "artemidiático", que é antes de tudo, um artista-pesquisador.

\section{Arte e Ciência em Guto Lacaz}

Entre os artistas brasileiros que desafiam e passeiam entre as fronteiras entre Arte e Ciência, trabalhando com meios múltiplos, podemos citar Abraham Palatnik, Lenora de Barros, Lygia Pape, Artur Matuck, Júlio Plaza, Waldemar Cordeiro e Guto Lacaz. Esse último, já teve grande aparição nos meios de comunicação de massa, com o quadro "Encontro entre a Arte e a Ciência", no programa Matéria Prima da TV Cultura nos anos 90; obras montadas em espaços públicos, como o Auditório para Questões Delicadas (1989), com cadeiras suspensas instaladas no Lago do Ibirapuera em São Paulo; realização de performances e ilustrações em diversos jornais e revistas brasileiros. Por tudo isso servirá aqui de exemplo de artista artemidiático, aquele que vai além dos usos comuns a que as máquinas se destinam, des- ou re- programando-as.

Em sua formação e em seu trabalho Guto Lacaz está no limiar Arte-Ciência. Graduado em eletrônica industrial e arquitetura, o artista explora em sua produção as possibilidades tecnológicas da arte - não o simples uso de tecnologia na arte, mas a tecnologia da arte, entendida como o conhecimento materializado na obra.

No objeto móbile construído em 1982, Óleo Maria à procura da salada, Lacaz usa uma lata de óleo comestível e a faz se deslocar pela borda de uma bandeja circular, movida por motor e rodinhas, tendo em cima uma miniatura de radar giratória. Já na instalação Eletro Esfero Espaço, realizada pela primeira vez na XIX Bienal Internacional de São Paulo, em 1987. A instalação 26 aspiradores de pó, dispostos em duas linhas de 13 aparelhos, sustentavam 26 esferas de isopor flutuando no ar e cada visitante atravessava um tapete vermelho ouvindo a pela "Tannhauser" de Richard Wagner em um walkman.

Nesses dois objetos tomados como exemplo, além de demandar conhecimentos de mecânica e eletrônica, o trabalho traz a intenção poética indispensável à obra de arte. É ao lidar com esses conceitos de forma lúdica que o artista leva o fruidor da obra à reflexão e a exercitar a percepção, construindo conhecimento sensível, aqui entendido como o processo cognitivo estimulado pelas sensações e todos os órgãos dos sentidos. Para João Pedrosa, "todo o clima 'low-tech' que permeia os seus trabalhos, sejam construções, ilustrações ou pintura (fios, pregos, pequenos 'gadcets' elétricos, truques luminosos, lâmpadas, pilhas, discos etc.) tem uma razão fortíssima para existir. Eles comentam plasticamente um dos temas mais importantes do nosso tempo: $\mathrm{O}$ mito do progresso (tecnológico, informático, atômico)". (PEDROSA, 1987, p.38-41).

Lacaz e seus objetos inusitados, para alguns críticos quase dadaístas, propõem a reflexão sobre o homem urbano contemporâneo e suas máquinas nem sempre maravilhosas. "Muito dos meus trabalhos tem motor e recurso eletrônico. É um comentário sobre tecnologia e cotidiano", declarou o artista ao repórter Gustavo Miller, do caderno Link do jornal O Estado de S. Paulo (MILLER, 2006, p. L14). "Meu mundo é esse: ciência e arte. Eu chamo de arte-tecnologia". 
A nomenclatura que realmente permanecerá para essa modalidade de criação Artemídia, Mídia-arte ou Arte Tecnologia, sem ou com hífen como usou Lacaz - será estabelecida pelo tempo, pela História da Arte. Seja qual for a "etiqueta", os artistas contemporâneos que pesquisam nessa seara têm todos um objetivo comum: deixar claro que a Arte já não pode ser apenas entendida como a "ciência do belo" ou uma simplória vazão de emoções. A Arte constrói conhecimento e caminha lado a lado com a Ciência. Nas palavras de Jacob Bronowski:

Há um fio que percorre continuamente todas as culturas humanas que conhecemos e que é feito de dois cordões. Esse fio é o da ciência e da arte. (...) Este emparelhamento indissolúvel exprime, por certo, uma unidade essencial da mente humana evoluída. (apud ZAMBONI, 2001, p. 20).

\section{Outros experimentos}

Sendo também uma pesquisa jornalística, o projeto "Artemídia Veemente" está também atuando junto à Assessoria de Comunicação e Imprensa da universidade bem como no Jornal da Unesp para por em prática a divulgação das pesquisas do Instituto de Artes.

Como uma primeira ação, algumas das pesquisas concluídas em 2005 foram transformadas em pautas jornalísticas. Nesta etapa, o critério de seleção empregado pelo coordenador de imprensa da Unesp, Oscar D’Ambrosio, também supervisor jornalístico do projeto, foi sua relevância do ponto de vista jornalístico, ou seja, se contém conceitos, informações ou abordagem inéditos.

Após a seleção prévia, a pesquisadora está realizando entrevistas com os pesquisadores, seus orientadores e representantes de entidades envolvidas na pesquisa. Uma das pesquisas que se encontra em processo de reportagem é o vídeo-dissertação Do indio aos arcos: um olhar artemidiático (Figura 1), o primeiro Trabalho Equivalente do Instituto de Artes da Unesp, produzido e defendido pela pesquisadora e videomaker Claudia Garrocini em 2005. O trabalho trata das obras de arte pública da avenida Paulista e seu título se refere às obras Índio Pescador (1940), de Francisco Leopoldo e Silva, a primeira do trajeto, e Caminhos (1991), de Lilian do Amaral Nunes e Jorge Bassani. O volume impresso da dissertação traz a capa assinada por outra pesquisadora do IA, Ana Cristina Paula Lima, que utilizou a imagem da escultura em bronze "O Caixeiro" (1991), de Domenico Calabrone (1928-2000).

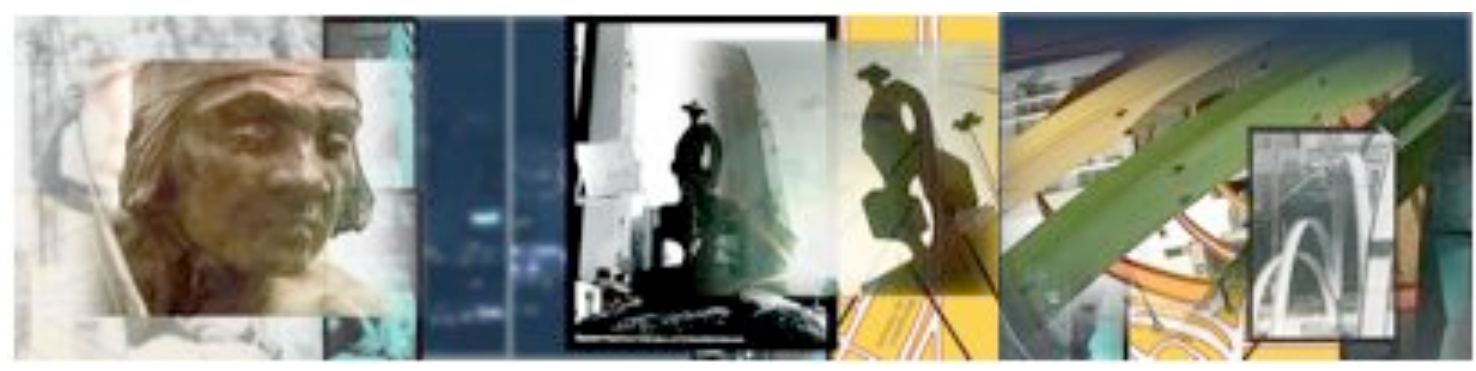

Figura 1- Seqüência do vídeo "Do Índio aos Arcos: um olhar artemidiático", de Claudia Garrocini.

Lançando um novo olhar sobre a avenida Paulista, a pesquisadora documentou as obras de arte pública da avenida-símbolo, redescobrindo a beleza e contando a história que há por trás de cada obra. A pesquisa revelou que muitas obras, mesmo sendo públicas, foram isoladas do contato direto com os passantes ou se encontram mal conservadas. Para 
propor soluções, Claudia Garrocini entrevistou o artista-pesquisador João Espinelli, especialista em arte pública e também professor do IA-Unesp. Além da publicação da reportagem no Portal Unesp, a idéia da divulgação da pesquisa é permitir que o vídeo que resultou da dissertação seja exibido publicamente.

Ao longo do processo pauta-reportagem-edição-publicação, os textos serão avaliados qualitativamente e num segundo momento servirão de instrumento para divulgação em mídia especializada, com o objetivo de transformar o Instituto de Artes e seu LaboratorIA - Laboratório de Ensino e Pesquisa em Artes Visuais em fontes de informação e disseminação de conhecimento para jornalistas, divulgadores de ciência e, por tudo o que foi aqui exposto, historiadores da arte.

\section{Referências Bibliográficas}

MILLER, Gustavo. Arte feita de tecnologia e escárnio. Entrevista com Guto Lacaz. O Estado de S. Paulo, São Paulo, 20 fev. 2006, página L14.

GARROCINI, Claudia. Do indio aos arcos: um olhar artemidiático. Dissertação de Mestrado e Video. Instituto de Artes da Unesp, São Paulo, 2005.

PEDROSA, João. Arguto e sagaz: Guia das Artes, São Paulo: Casa Editorial Paulista, v. 2, n. 7, p. 38-41, 1987.

SANTILLANA, G. O papel da Arte no Renascimento Cientifico. São Paulo: FAU/USP, s/d.

ZAMBONI, Silvio. A Pesquisa em Arte: um paralelo entre arte e ciência. 2. ed. Campinas: Autores Associados, 2001. 